in vivo $32: 1223-1230(2018)$

doi:10.21873/invivo.11368

\title{
Mechanical Thrombectomy of Large Artery Occlusion Is Beneficial in Octogenarians
}

\author{
SIMO KARHI ${ }^{1,2^{*}}$, OSSI NERG ${ }^{3,4^{*}}$, TUULI MIETTINEN ${ }^{3,4}$, EMMI MÄKIPAAKKANEN $^{3,4}$, \\ MIKKO TAINA ${ }^{1,2}$, HANNU MANNINEN $^{1,2}$, RITVA VANNINEN $^{1,2}$ and PEKKA JÄKÄLÄ ${ }^{3,4}$ \\ ${ }^{1}$ Department of Clinical Radiology, and ${ }^{4}$ Neuro Center, Kuopio University Hospital, Kuopio, Finland; \\ Units of ${ }^{2}$ Radiology and ${ }^{3}$ Neurology, Institute of Clinical Medicine, University of Eastern Finland, Kuopio, Finland
}

\begin{abstract}
Aim: Recent trials have established the benefit of endovascular treatment (EVT) for patients with acute ischemic stroke (AIS) due to large artery occlusion (LAO). However, older patients were often excluded from trials. EVT outcomes were retrospectively compared between octogenarians and younger patients treated for LAO in a tertiary hospital. Patients and Methods: A total of 199 consecutive patients with anterior circulation AIS that underwent EVT between 2009 and 2015 in the Kuopio University Hospital were included. Patients were dichotomized into younger $(<80$ years, $N=162)$ and older ( $\geq 80$ years, $N=37)$ groups. Baseline, imaging, and procedural characteristics, the 3-month modified Rankin Scale (mRS), and 1-year mortality were assessed. To conduct a number-needed-to-treat (NNT) analysis, data on agedichotomized control groups from a meta-analysis were acquired. Results: Compared to younger patients, older patients exhibited atrial fibrillation ( $57 \%$ vs. $21 \%, p<0.01)$ and coronary artery disease $(49 \%$ vs. $20 \%, p<0.01)$ more frequently and Internal Carotid Artery (ICA) occlusion less frequently $(22 \%$ vs. $55 \%, p<0.01)$. Similar proportions of patients received preprocedural intravenous recombinant tissue-type plasminogen activator (r-tPA; 57\% vs. 67\%), general anesthesia (35\% vs. 41\%), and reperfusion (Thrombolysis in Cerebral Infarction scale 2b/3; $76 \%$ vs. 75\%). Older patients had more complications during hospitalization (41\% vs. 24\%, $p=0.034$ ), higher 3-month $\mathrm{mRS}$ values $(4.0 \pm 2.3$ vs. $2.8 \pm 1.9, p<0.01)$, fewer favorable $m R S$
\end{abstract}

This article is freely accessible online.

*These Authors contributed equally to this work.

Correspondence to: Simo Karhi, B.M. Department of Clinical Radiology, Kuopio University Hospital, Puijonlaaksontie 2, 70210 Kuopio, Finland. E-mail: simkar@student.uef.fi

Key Words: Cerebrovascular stroke, thrombectomy, elderly, octogenarian, endovascular procedures, cerebral infarction. values ( $m R S \leq 2: 27 \%$ vs. $52 \%, p<0.01)$, and higher $3-m o n t h$ (46\% vs. $10 \% p<0.01)$ and 1-year mortality (49\% vs. $11 \%$, $p<0.01)$. The NNT to achieve an additional patient with an independent outcome ( $m R S \leq 2)$ was 12 among older and six among younger patients. Conclusion: Despite a poor recovery rate, octogenarians benefitted from EVT for AIS, with a NNT comparable to that of younger patients treated with intravenous $r$-tPA.

Stroke was the third leading cause of disability in the year 2015 , and it remains the second highest cause of mortality worldwide, claiming over $10 \%$ of all deaths $(1,2)$. Rapid administration of intravenous recombinant tissue-type plasminogen activator ( $\mathrm{r}-\mathrm{tPA}$ ) is the first-line treatment for eligible patients within the therapeutic time frame of $4.5 \mathrm{~h}$. Within $6 \mathrm{~h}$ of symptom onset, additional endovascular treatment $(\mathrm{EVT})$ with a stent retriever can be performed in patients with large artery occlusion (LAO) (3). Recent prospective trials studied EVT efficacy for clinically-selected patients with acute ischemic stroke (AIS) that had developed a carotid or proximal LAO with a small infarct core and sufficient collateral flow. They demonstrated that an EVT provided substantially better outcomes compared to treating with intravenous r-tPA alone (4-8). In addition, a recent metaanalysis suggested that for LAO, the time window for performing an additional EVT could be extended up to $7.3 \mathrm{~h}$ after symptom onset without compromising the beneficial results (9). The recent DAWN trial results supported the use of a mechanical thrombectomy within a 24-h time window for patients with a persistent significant penumbra, demonstrated with multimodal imaging (10).

The prevalence and incidence of AIS increases with age. Patients over 85 years old comprise $17 \%$ of all patients with stroke (11). Although the literature on EVT is encouraging, very old patients were often either excluded from larger trials, due to a predetermined upper age limit $(6,7)$, or they represented only a small proportion of the study population $(4,5,8)$. Some recent studies have indicated that EVT carried a significantly higher risk of mortality and morbidity for octogenarians (i.e. 
patients aged over 80 years) compared to younger patients, despite a successful recanalization (12-14). On the other hand, octogenarians seemed to benefit more from EVT compared to the standard r-tPA treatment alone (15). Even among the oldest patients (over 90 years old), an excellent prestroke functional status was associated with a reasonable chance of favorable EVT results (16). Consistent with the earlier studies, a 2016 HERMES meta-analysis, which combined data from five large RCTs, showed that EVT treatment was significantly more beneficial than rtPA alone among patients 80 years or older (17).

Several studies have shown that advanced age is a remarkable overall risk factor for poor functional EVT outcomes. Nevertheless, no definitive guidelines currently exist that address which older patients should be selected for intra-arterial recanalization therapy or what level of pre-stroke functional status is required to obtain beneficial results. At our university hospital, the decision to perform EVT for AIS is based on similar criteria for older and younger patients. The aim of this retrospective, single-center, registry study was to compare EVT results between octogenarians and patients under age 80 years. We also studied the correlation between the observation of leptomeningeal collateral flow on admission images and clinical outcome after EVT.

\section{Materials and Methods}

Study design. This retrospective registry study was approved by the Kuopio University Hospital Research Ethics Board (no. 5772789). All clinical investigations were conducted according to the principles expressed in the Declaration of Helsinki. Between September 2009 and December 2015, among an estimated 4,000 consecutive patients admitted to our tertiary hospital with intention-to-treat AIS, patients with LAO were selected to undergo an endovascular reperfusion procedure. Prior to EVT, all patients routinely underwent similar examinations, with no distinction between older and younger patients. On admission, a neurologist evaluated the clinical status, based on the National Institute of Health Stroke Scale (NIHSS) (18) and multimodal imaging, including non-contrast computed tomography (NCCT), cervicocranial computed tomographic angiography (CTA), and computed tomographic perfusion imaging (CTP; from 2012). Individual treatment decisions were based on the symptom onset time, the travel distance to the hospital, other underlying diseases, and the prestroke functional status (Table I) (19).

Patients. Consecutive patients with AIS were selected for EVT when a CTA confirmed vessel occlusion, when the penumbra was considered salvageable, and when the infarct core was not substantially large. The NIHSS status was evaluated at the onset of stroke. Of these consecutive EVT-treated patients $(\mathrm{N}=261)$, the following inclusion criteria were used to select patients for the present study: age 18 years or older; a LAO in the middle cerebral artery (MCA; M1 or M2 segment) or in the internal carotid artery (ICA), with or without an intracranial thrombus component, confirmed on the admission imaging; and available follow-up information for 1 year after the AIS onset.

Sixty-two patients that underwent EVT were excluded due to the following: age under 18 years in two; a posterior circulation occlusion in 43; a stroke due to etiology other than LAO in seven (of which three were anterior A2 segment and four M3 segment occlusions); follow-up data not accessible in five; secondary AIS occurring as a complication of neurosurgical treatment in three; and recurrent stroke during the studied timeline in two cases. The remaining 199 patients (76 females; mean age 67.0 12.9 years) were dichotomized by age; the younger group comprised those under 80 years old $(\mathrm{N}=162)$ and the older group comprised those 80 years old or more (octogenarians, $\mathrm{N}=37)$. The latter group included three patients over 90 years old (91, 92, and 95 years); no upper limit for patient age was set.

Endovascular procedures. EVT interventions were performed in a dedicated biplane neuroangio suite (Siemens Healthcare, Erlangen, Germany) under general anesthesia or conscious sedation. An 80-cm long introducer sheath (Cook 8F/80; Cook Incorporated, Bloomington, Indiana, USA) and a multipurpose shape guiding catheter were introduced into the cervical ICA over a 5 Fr JR4 diagnostic catheter (Cordis, Miami, FL, USA). A thrombectomy aspiration catheter (5 MAX, 5 MAX 60 or 68; Penumbra Inc., Alameda, CA, USA) was advanced to the occlusion over a Neuro Slider 21 (Acandis, Pforzheim, Germany) or a Prowler Select Plus microcatheter (Codman \& Shurtleff Inc., Raynham, MA, USA), with the aid of a 0.014-inch microguidewire (Transend EX or Synchro, Stryker, Fremont, CA, USA). The first attempt to remove the thrombus was usually performed with vacuum aspiration, but when that method was not technically feasible or ineffective, a stent retriever was used (Solitaire, Medtronic, Minneapolis, MN, USA; or Trevo, Stryker). In addition, during removal with the stent retriever and/or inner coaxial catheters, manual aspiration through the $8 \mathrm{Fr}$ guiding catheter was invariably performed. In cases where an underlying atherosclerotic occlusion was present in the proximal ICA, a balloon dilation was performed, followed by stent placement with a filter (Carotid Wallstent and FilterWire, Boston Scientific, Marlborough, MA, USA), typically in the last stage of the intervention.

Patient and procedural characteristics. Based on the medical history and prescribed medications, we recorded each patient's age, gender, and any manifestation of medically treated hypertension, diabetes, hypercholesterolemia, known atrial fibrillation (AF), or coronary artery disease (CAD). Postprocedural reperfusion was considered successful when a score of $2 b$ or 3 was achieved on the Thrombolysis in Cerebral Infarction (TICI) scale (20). The modified Rankin scale (mRS) was used to measure the degree of disability, based on the guidelines from the American Stroke Association $(3,21)$. One-year mortality was evaluated based on each patient's medical history data. Procedural complications consisted of nine limited vascular dissections and 10 vascular perforations with hemorrhage. Nine other non-specific complications were recorded; these were related to instrumental failure, difficult vascular spasms, or other intracerebral hemorrhages. Postprocedural complications were studied separately; they consisted of 14 reperfusion hemorrhages, one subdural hematoma, two puncturesite hemorrhages, six non-specific hemorrhages from other organs, and 30 other complications, including heart failure, epileptic seizure, pneumonia or other infections, and elevated intracranial pressure due to edema with or without hemicraniectomy.

Collateral score analysis. A single observer (SK), blinded to the retrospective clinical information, evaluated CTA source images with the collateral score (CS) system, according to Souza et al. (22) $(\mathrm{CS}=0$ : Absent collaterals in $>50 \%$ of affected M2 vascular region; $\mathrm{CS}=1$ : diminished collaterals in $>50 \%$ of $\mathrm{M} 2$ region; $\mathrm{CS}=2$ : 
Karhi et al: EVT in Stroke Is Beneficial in Octogenarians

Table I. Baseline characteristics of the total study population and separate groups of younger ( $<80$ years) and older ( $\geq 80$ years) individuals.

\begin{tabular}{|c|c|c|c|c|}
\hline Characteristic & Total $(n=199)$ & Age $<80$ years $(n=162)$ & Age $\geq 80$ years $(n=37)$ & $p$-Value \\
\hline Age, years, mean $\pm \mathrm{SD}$ & $67.0 \pm 12.9$ & $63.2 \pm 11.1$ & $84.0 \pm 3.3$ & $<0.01$ \\
\hline Female, n $(\%)$ & $76(38.2)$ & $47(29.0)$ & $29(78.4)$ & $<0.01$ \\
\hline Baseline mRS, mean \pm SD & $0.30 \pm 67$ & $0.26 \pm 65$ & $0.46 \pm 73$ & 0.026 \\
\hline Pre-procedural NIHSS, mean \pm SD $(\mathrm{N}=191)$ & $14.0 \pm 6.0$ & $12.7 \pm 6.1$ & $14.1 \pm 5.8$ & 0.203 \\
\hline Atrial fibrillation, $\mathrm{n}(\%)$ & $55(27.6)$ & $34(21.0)$ & $21(56.8)$ & $<0.01$ \\
\hline Hypertension, $\mathrm{n}(\%)$ & $131(65.8)$ & $107(66.0)$ & $24(64.9)$ & 0.891 \\
\hline Coronary artery disease, $\mathrm{n}(\%)$ & $50(25.1)$ & $32(19.8)$ & $18(48.6)$ & $<0.01$ \\
\hline Hyperlipidemia, n (\%) & $102(51.3)$ & $85(52.5)$ & $17(45.9)$ & 0.474 \\
\hline Diabetes, n (\%) & $41(79.4)$ & $34(21.0)$ & 7 (18.9) & 1.000 \\
\hline Earlier AIS within 3 months, $\mathrm{n}(\%)$ & $9(4.5)$ & $8(4.9)$ & $1(2.7)$ & 1.000 \\
\hline Any history of stroke, n (\%) & $30(15.1)$ & $25(15.4)$ & $5(13.5)$ & 1.000 \\
\hline M1 occlusion, $\mathrm{n}(\%)$ & $64(32.2)$ & $44(27.2)$ & $20(54.1)$ & 0.012 \\
\hline M2 occlusion, n (\%) & $38(19.1)$ & $29(17.9)$ & $9(24.3)$ & 0.362 \\
\hline ICA based occlusion, n (\%) & $97(48.7)$ & $89(54.9)$ & $8(21.6)$ & $<0.01$ \\
\hline $\mathrm{CS}$, mean $\pm \mathrm{SD}(\mathrm{n}=194)$ & $1.85 \pm 1.2$ & $1.87 \pm 1.2$ & $1.81 \pm 1.1$ & 0.859 \\
\hline Poor collaterals $(\mathrm{CS}=0), \mathrm{n}(\%)(\mathrm{N}=194)$ & $31(16.0)$ & $25(15.9)$ & $6(16.2)$ & 1.000 \\
\hline Good collaterals $(\mathrm{CS} \geq 3), \mathrm{n}(\%)$ & $62(32.0)$ & $52(33.1)$ & $10(27.0)$ & 0.559 \\
\hline
\end{tabular}

SD: Standard deviation, NIHSS: National Institute of Health Stroke Scale, mRS: modified Rankin Scale, AIS: acute ischemic stroke; ICA: internal carotid artery; CS: Collateral Score, ns: not significant.

Table II. Comparison of procedural and outcome characteristics between the younger ( $<80$ years) and older ( $\geq 80$ years) age groups.

\begin{tabular}{|c|c|c|c|c|}
\hline Characteristic & Total $(n=199)$ & Age $<80$ years $(n=162)$ & Age $\geq 80$ years $(n=37)$ & $p$-Value \\
\hline Preoperative $i . v$. thrombolysis, $\mathrm{n}(\%)$ & $130(65.3)$ & $109(67.3)$ & $21(56.8)$ & 0.225 \\
\hline General anesthesia, $\mathrm{n}(\%)$ & $79(39.7)$ & $66(40.7)$ & $13(35.1)$ & 0.529 \\
\hline Onset-to-groin-puncture time $(\min )$, mean $\pm \mathrm{SD}(\mathrm{n}=178)$ & $292.5 \pm 238.5$ & $306.9 \pm 256.0$ & $221 \pm 89.6$ & 0.021 \\
\hline Onset-to-reperfusion time $(\min )$, mean $\pm S D(n=140)$ & $337.9 \pm 164.3$ & $348.8 \pm 176.7$ & $289.6 \pm 77.9$ & 0.060 \\
\hline TICI $2 \mathrm{~b}$ or $3, \mathrm{n}(\%)(\mathrm{n}=196)$ & $149(76.0)$ & $121(74.7)$ & $28(75.7)$ & 1.000 \\
\hline Procedural complications, $\mathrm{n}(\%)$ & $28(14.1)$ & $22(13.6)$ & $6(16.2)$ & 0.677 \\
\hline Hospital-time complications, $\mathrm{n}(\%)$ & $53(26.6)$ & $38(23.5)$ & $15(40.5)$ & 0.034 \\
\hline Any complication, $\mathrm{n}(\%)$ & $69(34.7)$ & $51(31.5)$ & $18(49)$. & 0.048 \\
\hline 3-Month mRS score, mean \pm SD & $2.8 \pm 2.0$ & $2.5 \pm 1.9$ & $4.0 \pm 2.3$ & $<0.01$ \\
\hline 3-Month mRS-score $\leq 2, \mathrm{n}(\%)$ & $94(47.7)$ & $84(51.9)$ & $10(27.0)$ & $<0.01$ \\
\hline 3-Month mRS-score $\leq 3, \mathrm{n}(\%)$ & $123(61.8)$ & $110(67.9)$ & $13(35.1)$ & $<0.01$ \\
\hline Absolute change in mRS, mean $\pm \mathrm{SD}$ & $2.5 \pm 2.0$ & $2.2 \pm 1.9$ & $3.5 \pm 2.4$ & $<0.01$ \\
\hline Mortality at 3 months, $\mathrm{n}(\%)$ & $33(16.6)$ & $16(9.9)$ & $17(45.9)$ & $<0.01$ \\
\hline One-year mortality, n (\%) & $36(18.1)$ & $18(11.1)$ & $18(48.6)$ & $<0.01$ \\
\hline
\end{tabular}

SD: Standard deviation, mRS: modified Rankin Scale, CS: Collateral Score. TICI: Thrombolysis in Cerebral Infarction scale, ns: not significant.

diminished collaterals in $<50 \%$ of $\mathrm{M} 2$ region; $\mathrm{CS}=3$ : collateral abundance equal to that on the contralateral side; and $\mathrm{CS}=4$ : collateral abundance greater than that on the contralateral side). The scores were further dichotomized into categories of malignant $(\mathrm{CS}=0)$ versus other $(\mathrm{CS}>0)$, and poor $(\mathrm{CS}<2)$ versus good $(\mathrm{CS} \geq 2)$ (23). To test interobserver reproducibility, an experienced radiologist (HM) evaluated the CSs of 107 randomly selected patients.

Statistical analysis. Continuous variables are presented as the mean $\pm \mathrm{SD}$, and categorical variables are presented as the absolute frequencies or percentages. The Mann-Whitney $U$-test was used to compare groups when the values were not normally distributed, based on the Kolmogorov-Smirnov test. The Spearman correlation coefficient was used to compare continuous CSs to NIHSS scores and 3-month mRS values. Pearson's chi-square test was used to investigate associations between nominal variables. Fisher's exact test was used when appropriate. Statistical significance was set at $p<0.05$, and a high statistical significance was set at $p<0.01$. The intraclass correlation coefficient (ICC) was used to determine interobserver agreement between CS evaluations. Data were analyzed with SPSS for Macintosh (version 24; SPSS Inc., Chicago, IL, USA). 
Multiple linear regression analyses were performed only when the data met the following assumptions: linearity, independence, normally distributed, and equal variance of residuals in the outcome variable. The number needed to treat (NNT) values were calculated from the absolute difference between groups in risk of reaching favorable (i.e. $\leq 2$ ) and unfavourable (i.e. >2) 3-month follow-up mRS scores. Data on age-matched control groups that received only standard care were acquired from a meta-analysis that focused on patients treated with the Solitaire ${ }^{\mathrm{TM}}$ Revascularization Device from the ESCAPE, REVASCAT, SWIFT-PRIME, and EXTEND-IA trials (5-8, 24). These four trials included 54 control patients, 80 years or older, who did not undergo EVT.

\section{Results}

The baseline characteristics of the dichotomized study population $(\mathrm{N}=199)$ are presented in Table I and procedural and outcome characteristics in Table II. The mean ages were $84.0 \pm 3.3$ years in the older group ( $\geq 80$ years old, $N=37$ ), and $63.2 \pm 11.1$ years in the younger group (under 80 years old, $\mathrm{N}=162$ ). There was a higher proportion of females among the octogenarians $(78 \% v s .29 \% p<0.01)$. Among all patients, the mean age differed significantly between genders (females: $72.9 \pm 13.9$ years $v s$. males: $63.4 \pm 10.8$ years $p \leq 0.01$ ). The mean of reconstructed $\mathrm{mRS}$ scores prior to the stroke were $0.5 \pm 0.7$ in the older group and $0.3 \pm 0.7$ in the younger group $(p=0.026)$. No significant difference between study groups was observed in the proportions of patients with hypertension, diabetes, hypercholesterolemia, or an earlier stroke history, but the older group had significantly higher prevalence of CAD (49\% vs. $20 \%, p<0.01)$ and $\mathrm{AF}(57 \%$ vs. $21 \%, p<0.01)$. The mean preprocedural NIHSS points were $14.1 \pm 5.8$ in the older group and $12.7 \pm 6.1$ in the younger group ( $p=n s)$. Successful reperfusion (TICI 2 b or 3 ) was achieved in $75.7 \%$ of the older group and $74.7 \%$ of the younger group $(p \geq 0.05)$. The mean onset-to-groin-puncture time was $221 \pm 89.6 \mathrm{~min}$ for the older group $(\mathrm{N}=30)$, which was significantly shorter than the mean time for the younger group $(349 \pm 177 \mathrm{~min}, \mathrm{~N}=148, p=0.021)$. The mean onset-to-reperfusion time did not differ between the

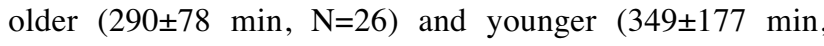
$\mathrm{N}=114)$ groups $(p \geq 0.05)$. Occlusions occurred significantly less often in the ICA $(22 \% v s .55 \%, p<0.01)$ and significantly more often in the M1 (54\% vs. $27 \%, p<0.01)$ in the older group compared to the younger group. No statistically significant difference was observed between groups in the frequency of M2 occlusions.

The NNT for a favorable clinical outcome was 12 in the older group and 6 in the younger group. The mean 3-month follow-up $\mathrm{mRS}$ scores were significantly higher in the older group (4.0 2.2 vs. $2.5 \pm 1.9, p<0.01$, Figure 1). Favorable 3month follow-up mRS scores (i.e. $\leq 2)$ were achieved less often in the older group than in the younger group (27\% vs. $52 \%, p<0.01)$. Based on a comparison of the mRS points measured prestroke and at 3 months after the AIS, the older group exhibited greater absolute deterioration than the younger group (3.5 \pm 2.4 vs. $2.2 \pm 1.9, p<0.01)$. Patient age was significantly correlated with the 3 -month $\mathrm{mRS}$ score $(\mathrm{r}=0.26$, $p<0.01)$. In the total patient population, males had better 3-

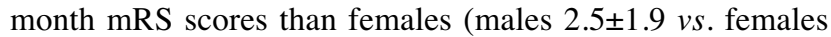
$3.2 \pm 2.2, p=0.036)$. However, this difference between sexes was not observed when the age groups were analyzed separately. The 3-month $\mathrm{mRS}$ scores of males and females were $2.4 \pm 1.8$ and $2.7 \pm 2.1$ in the younger group $(p \geq 0.05)$, and $4.3 \pm 2.6 v s .3 .9 \pm 2.3$ in the older group $(p \geq 0.05)$, respectively. The deterioration in $\mathrm{mRS}$ points did not differ between male $(2.4 \pm 2.0)$ and female $(2.8 \pm 3.0)$ patients $(p \geq 0.05)$. When homoscedasticity, linearity, and equal variance assumptions were not met, multiple linear regression analyses on 3-month mRS scores could not be performed.

Mortality was significantly higher in the older group than in the younger group after 3 months $(46 \% v s .9 .9 \%, p<0.01)$ and after 1 year $(49 \%$ vs. $11 \%, p<0.01)$. One-year mortality did not significantly vary between male $(17 \%)$ and female patients $(24 \%, p \geq 0.05)$. The incidence of complications during the intra-arterial procedure did not differ between groups, but complications following hospitalization occurred more frequently in the older group than in the younger group (41\% vs. $23 \% p<0.034)$. A similar difference was observed between groups in the frequency of total complications (combined procedural/in-hospital occurrences: $49 \%$ vs. $31 \%$, respectively, $p=0.048$ ).

The two evaluators of collateral scores achieved an ICC of $0.71(p<0.01)$. In the younger group, the CSs were inversely correlated with admission NIHSS scores $(\mathrm{r}=-0.354, p<0.01)$ and 3 -month $\mathrm{mRS}$ values $(\mathrm{r}=-0.212, p<0.01)$. However, in the older group, no significant correlations were observed ( $p \geq 0.05$; Figures 2 and 3 ). In the younger group, patients with malignant CS had significantly higher admission NIHSS scores than patients with other CS (NIHSS scores: 15.3 \pm 4.5 vs. $12.2 \pm 6.2 ; p=0.014)$. Similarly, younger patients with poor CS had significantly higher admission NIHSS and 3-month $\mathrm{mRS}$ values compared to patients with good CS (NIHSS: $15.2 \pm 5.0$ vs. $11.0 \pm 6.2, p<0.01$; mRS: $2.8 \pm 1.8$ vs. $2.2 \pm 1.8$, $p=0.037)$. No other significant differences were found between the CS categories for other variables.

\section{Discussion}

The important role of mechanical thrombectomy in the care of AIS was established in the large prospective randomized controlled trials of 2015, which started a new era in stroke treatment (3-8). However, patients over 80 years old played only a minor role in those analyses; consequently, to date, no exact guidelines exist for EVT treatment in very aged individuals. In the present single-center retrospective study, we examined the results of thrombectomy in 199 consecutive patients treated for AIS. The efficacy of EVT between octogenarians and patients under 80 years old was compared. 


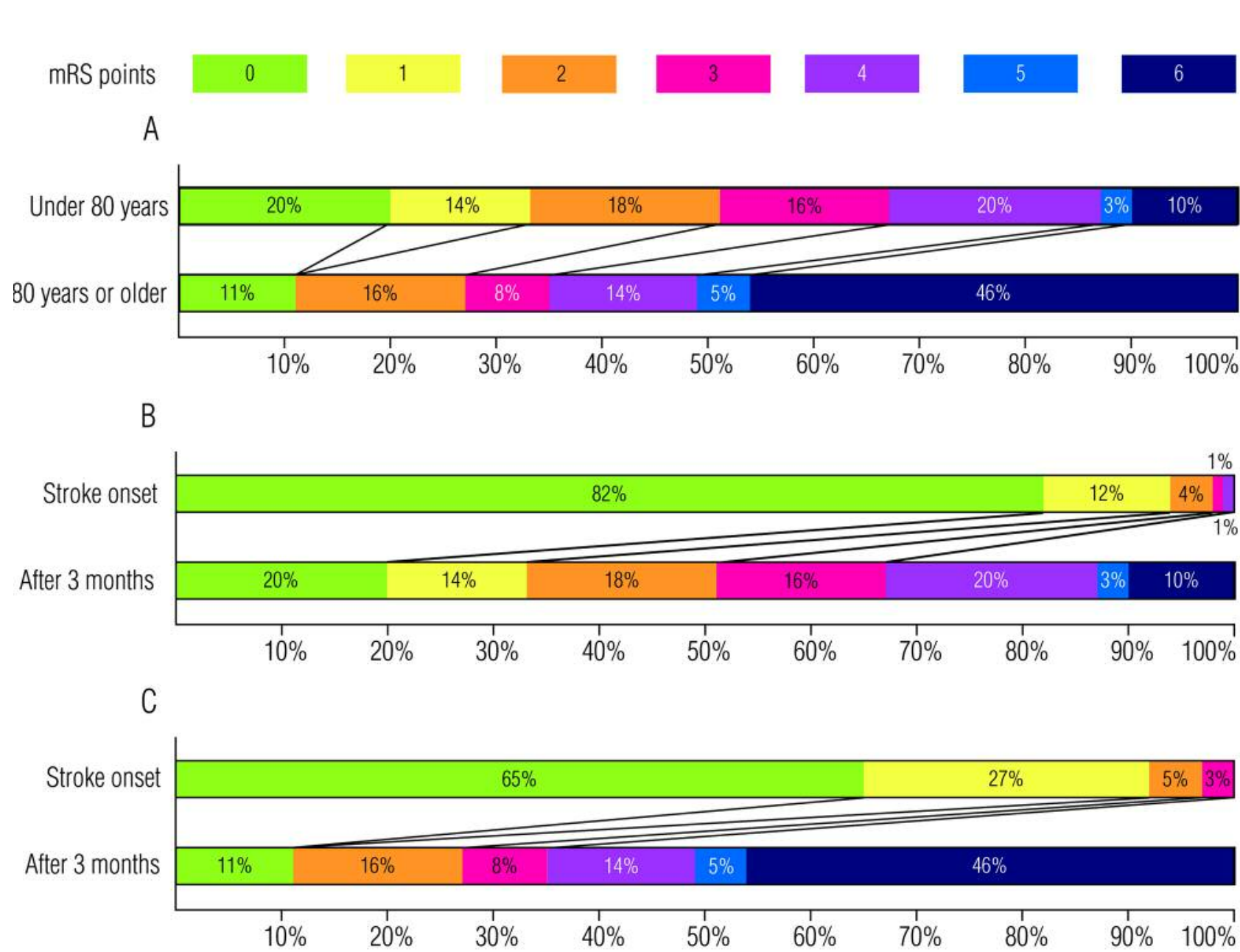

Figure 1. Functional outcome before and after thrombectomy for acute ischemic stroke. Distributions of modified Rankin Scale (mRS) points for both groups (A) and change in mRS observed 3 months after the onset of stroke for the younger (B) and older (C) age groups.

We observed that a favorable 3-month $\mathrm{mRS}$ score (i.e. 0-2) was achieved more often in the younger group than in the older group. In addition, age above 80 years proved to be a remarkable risk factor for a poor functional outcome after EVT. However, despite that risk factor, 10 out of the 37 older patients achieved a favorable result. In addition, the calculated NNT for achieving a favorable 3-month mRS was 12 in patients over 80 years old, and six in younger patients. This latter comparison was performed with a control group that received standard treatment with $\mathrm{r}$-tPA alone. Thus, our results indicated that despite a poor prognosis, octogenarians clearly benefitted from EVT for AIS.

Older patients with AIS could be expected, in general, to exhibit worse overall performance compared to younger patients. In the present study, the decision to treat with EVT was based on criteria that did not distinguish age; thus, the two age groups underwent similar examinations. The main strength of the present study was the ability to compare the individual pre-stroke mRS scores, which reflected clinical status and functional performance, to the 3-month outcome. This comparison allowed an assessment of the absolute change in functional capacity provided by the EVT treatment. The two age groups exhibited similar symptom severity, indicated by the fact that the reconstructed pre-treatment NIHSS scores, which evaluated the difficulty of the stroke, were not significantly different between groups.

The results of the present single-center study paralleled those achieved in some earlier studies that focused on the usefulness of intra-arterial reperfusion therapy in older patients $(12,13,25,26)$. The studies conducted by Castonguay et al. (14), Duffis et al. (25) and Zeevi et al. (26) evaluated functional performance and recovery after AIS and demonstrated a worse outcome in older age groups than in younger age groups. At the same time, the recent 2016 HERMES meta-analysis, which combined data from five large random controlled trials, showed that in older individuals, 


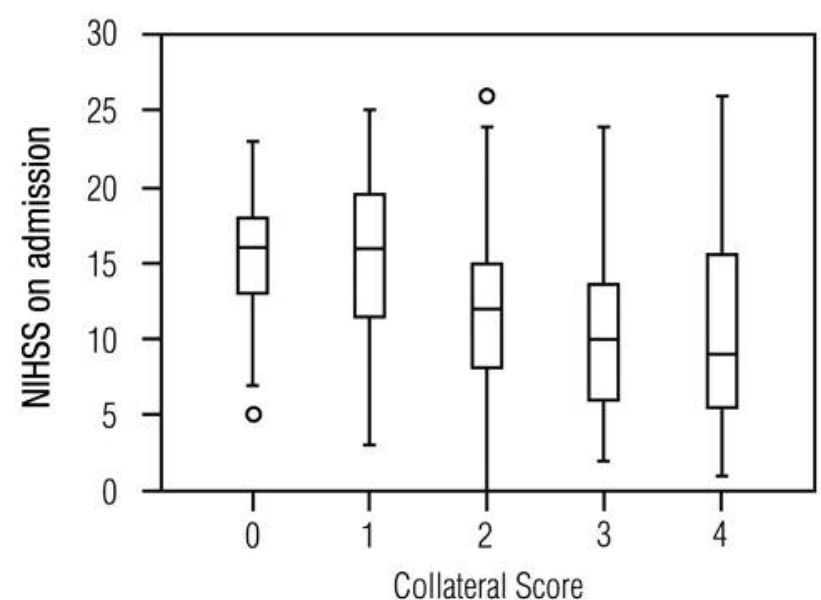

Figure 2. National Institute of Health Stroke Scale (NIHSS) points and Collateral Scores of patients aged under 80 years. Median NIHSS points (represented by horizontal lines) declined with increase in Collateral Scores of patients under 80 years old $(p<0.01)$, but not for older patients ( $p \geq 0.05$, not shown). Boxes mark the upper and lower quartiles and vertical bars represent the lowest and the highest values, circles representing outlier measurements.

EVT provided significantly more benefit and notably improved the prognosis compared to the standard treatment with r-tPA alone (17).

The 1-year mortality rates were significantly different between the age groups, to the benefit of the younger patients. This might partly be explained by the natural increase in mortality, due to age. Furthermore, males seemed to achieve a somewhat better recovery than females, although no difference was observed in the 1-year mortality between genders. Nevertheless, the younger group had a significantly higher proportion of males than the older group. The higher proportion of females in the older group reflected the longer average life expectancy of women in Finland.

In the younger group, the CS was inversely correlated with the admission NIHSS scores and 3-month mRS, but no similar trends were observed in the older group. Young patients with malignant or poor collaterals had significantly higher admission NIHSS scores. Poor collaterals predicted a higher 3-month mRS, but again, only in the younger group. The CS did not seem to predict the outcome of EVT as reliably in the older group as it did in the younger group. However, further studies should be conducted to confirm this finding due to the relatively limited number of older patients included in this study.

This study had several limitations that should be considered when interpreting the results. Firstly, the study was conducted at a single hospital, and a total of 62 patients out of 261 that underwent EVT were excluded because they did not meet the study criteria. Another limitation was the

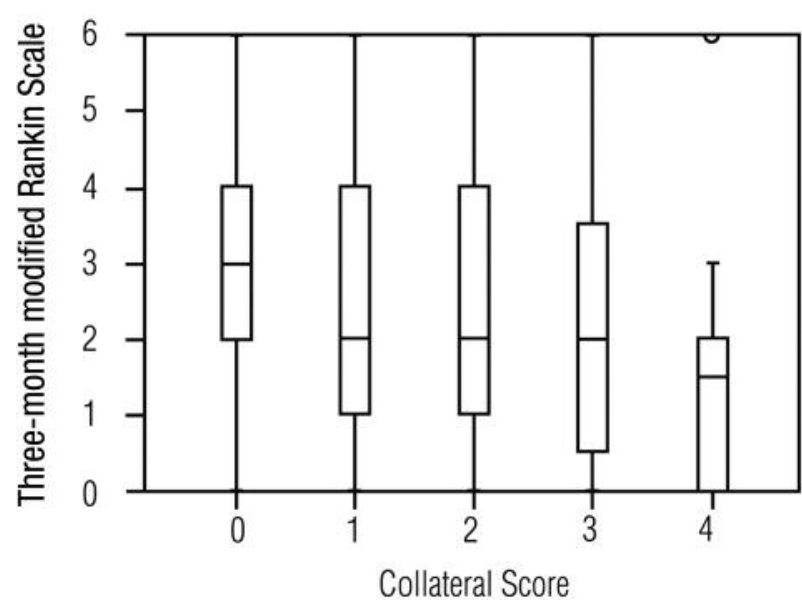

Figure 3. Functional outcome and Collateral Scores of patients aged under 80 years. Inverse relationship between collateral scores and median 3-month modified Rankin Scale points (represented by lines) for younger patients $(p<0.01)$, but not for older patients $(p \geq 0.05$, not shown). Boxes mark the upper and lower quartiles and vertical bars represent the lowest and the highest values, circles representing outlier measurements.

relatively small group of octogenarians (37 patients). The onset-to-groin-puncture time was significantly longer in the younger group compared to the older group $(221 \pm 90 \mathrm{~min} v s$. $307 \pm 256 \mathrm{~min}$ ). This probably reflected the fact that very old patients were seldom transported from other hospitals to our university hospital for thrombectomy. Despite that difference, the onset-to-reperfusion times were not significantly different between groups.

To date, the efficacy of EVT in older individuals has been investigated in a limited number of studies, and no exact international treatment guidelines have been established for treating this population. The incidence of stroke in older patients is predicted to increase substantially in the next few decades $(11,27)$. Therefore, knowledge on the effectiveness of treatment, procedural outcomes, and costs could prove valuable in the assessment of healthcare resources in the near future. Continuous EVT availability should be arranged at all university-level hospitals within reasonable distance from large populations. Moreover, high availability of EVT would benefit healthcare professionals by providing important experience with this therapy.

\section{Conclusion}

An age of 80 years and above predicted a significant increase in the risk of functional impairment and greater mortality after EVT for an anterior circulation LAO. We calculated that the NNT was 12 to achieve a 3-month mRS of 2 or less, compared to a control group that received the standard 
treatment alone. This NNT was comparable to the NNT of 14 for younger patients treated with an intravenous r-tPA to achieve an mRS of 1 or less, within a time window of 180$270 \mathrm{~min}$ (28) Therefore, the results of this single-center study indicated that despite a worse recovery rate compared to younger patients, a significant proportion of older patients indeed benefitted from EVT for AIS. In conclusion, an EVT should be carefully considered as a viable option for patients aged 80 years or more, when they meet the other indications for a thrombectomy.

\section{Funding}

This study was granted governmental funding by the Kuopio University Hospital Research Commission.

\section{Conflicts of Interest}

The Authors declare no conflicts of interest in regard to this study.

\section{Acknowledgements}

The Authors would like to thank Tuomas Selander for statistical guidance.

\section{References}

1 Global Health Estimates 2015: Disease burden by Cause, Age, Sex, by Country and by Region, 2000-2015. Geneva, World Health Organisation, 2016. http://www.who.int/healthinfo/ global_burden_disease/estimates/en/index2.html (Last accessed 3rd April 2018).

2 Global Health Estimates 2015: Deaths by Cause, Age, Sex, by Country and by Region, 2000-2015. Geneva, World Health Organisation, 2016. http://www.who.int/healthinfo/global_ burden_disease/estimates/en/index 1.html (Last accessed 10.1.2018).

3 Powers WJ, Derdeyn CP, Biller J, Coffey CS, Hoh BL, Jauch EC, Johnston KC, Johnston SC, Khalessi AA, Kidwell CS, Meschia JF, Ovbiagele B, Yavagal DR and American Heart Association Stroke Council: 2015 American heart Association/American stroke association focused update of the 2013 guidelines for the early management of patients with acute ischemic stroke regarding endovascular treatment. Stroke 46(10): 3020-3035, 2015.

4 Berkhemer OA, Fransen PS, Beumer D, van den Berg LA, Lingsma HF, Yoo AJ, Schonewille WJ, Vos JA, Nederkoorn PJ, Wermer MJ, van Walderveen MA, Staals J, Hofmeijer J, van Oostayen JA, Lycklama à Nijeholt GJ, Boiten J, Brouwer PA, Emmer BJ, de Bruijn SF, van Dijk LC, Kappelle LJ, Lo RH, van Dijk EJ, de Vries J, de Kort PL, van Rooij WJ, van den Berg JS, van Hasselt BA, Aerden LA, Dallinga RJ, Visser MC, Bot JC, Vroomen PC, Eshghi O, Schreuder TH, Heijboer RJ, Keizer K, Tielbeek AV, den Hertog HM, Gerrits DG, van den Berg-Vos RM, Karas GB, Steyerberg EW, Flach HZ, Marquering HA, Sprengers ME, Jenniskens SF, Beenen LF, van den Berg R, Koudstaal PJ, van Zwam WH, Roos YB, van der Lugt A, van Oostenbrugge RJ,
Majoie CB, Dippel DW, MR CLEAN Investigators: A randomized trial of intraarterial treatment for acute ischemic stroke. N Eng J Med 372(1): 11-20, 2015.

5 Goyal M, Demchuk AM, Menon BK, Eesa M, Rempel JL, Thornton J, Roy D, Jovin TG, Willinsky RA, Sapkota BL, Dowlatshahi D, Frei DF, Kamal NR, Montanera WJ, Poppe AY, Ryckborst KJ, Silver FL, Shuaib A, Tampieri D, Williams D, Bang OY, Baxter BW, Burns PA, Choe H, Heo JH, Holmstedt CA, Jankowitz B, Kelly M, Linares G, Mandzia JL, Shankar J, Sohn SI, Swartz RH, Barber PA, Coutts SB, Smith EE, Morrish WF, Weill A, Subramaniam S, Mitha AP, Wong JH, Lowerison MW, Sajobi TT, Hill MD and ESCAPE Trial Investigators: Randomized assessment of rapid endovascular treatment of ischemic stroke. N Eng J Med 372(11): 1019-1030, 2015.

6 Jovin TG, Chamorro A, Cobo E, de Miquel MA, Molina CA, Rovira A, San Román L, Serena J, Abilleira S, Ribó M, Millán M, Urra X, Cardona P, López-Cancio E, Tomasello A, Castaño C, Blasco J, Aja L, Dorado L, Quesada H, Rubiera M, Hernandez-Pérez M, Goyal M, Demchuk AM, von Kummer R, Gallofré M, Dávalos A and REVASCAT Trial Investigators: Thrombectomy within 8 hours after symptom onset in ischemic stroke. N Eng J Med 372(24): 2296-2306, 2015.

7 Saver JL, Goyal M, Bonafe A, Diener HC, Levy EI, Pereira VM, Albers GW, Cognard C, Cohen DJ, Hacke W, Jansen O, Jovin TG, Mattle HP, Nogueira RG, Siddiqui AH, Yavagal DR, Baxter BW, Devlin TG, Lopes DK, Reddy VK, du Mesnil de Rochemont $\mathrm{R}$, Singer OC, Jahan R and SWIFT PRIME Investigators: Stentretriever thrombectomy after intravenous t-PA $v s$. t-PA alone in stroke. N Engl J Med 372(24): 2285-2295, 2015.

8 Campbell BC, Mitchell PJ, Kleinig TJ, Dewey HM, Churilov L, Yassi N, Yan B, Dowling RJ, Parsons MW, Oxley TJ, Wu TY, Brooks M, Simpson MA, Miteff F, Levi CR, Krause M, Harrington TJ, Faulder KC, Steinfort BS, Priglinger M, Ang T, Scroop R, Barber PA, McGuinness B, Wijeratne T, Phan TG, Chong W, Chandra RV, Bladin CF, Badve M, Rice H, de Villiers L, Ma H, Desmond PM, Donnan GA, Davis SM and EXTENDIA Investigators: Endovascular therapy for ischemic stroke with perfusion-imaging selection. N Eng J Med 372(11): 1009-1018, 2015.

9 Saver JL, Goyal M, van der Lugt A, Menon BK, Majoie CB, Dippel DW, Campbell BC, Nogueira RG, Demchuk AM, Tomasello A, Cardona P, Devlin TG, Frei DF, du Mesnil de Rochemont R, Berkhemer OA, Jovin TG, Siddiqui AH, van Zwam WH, Davis SM, Castaño C, Sapkota BL, Fransen PS, Molina C, van Oostenbrugge RJ, Chamorro Á, Lingsma H, Silver FL, Donnan GA, Shuaib A, Brown S, Stouch B, Mitchell PJ, Davalos A, Roos YB, Hill MD and HERMES Collaborators: Time to treatment with endovascular thrombectomy and outcomes from ischemic stroke: A meta-analysis. JAMA 316(12): 1279-1289, 2016.

10 Jovin TG, Saver JL, Ribo M, Pereira V, Furlan A, Bonafe A, Baxter B, Gupta R, Lopes D, Jansen O, Smith W, Gress D, Hetts S, Lewis RJ, Shields R, Berry SM, Graves TL, Malisch T, Rai A, Sheth KN, Liebeskind DS and Nogueira RG: Diffusion-weighted imaging or computerized tomography perfusion assessment with clinical mismatch in the triage of wake up and late presenting strokes undergoing neurointervention with Trevo (DAWN) trial methods. Int J Stroke 12(6): 641-652, 2017.

11 Benjamin EJ, Blaha MJ, Chiuve SE, Cushman M, Das SR, Deo R, de Ferranti SD, Floyd J, Fornage M, Gillespie C, Isasi CR, 
Jiménez MC, Jordan LC, Judd SE, Lackland D, Lichtman JH, Lisabeth L, Liu S, Longenecker CT, Mackey RH, Matsushita K, Mozaffarian D, Mussolino ME, Nasir K, Neumar RW, Palaniappan L, Pandey DK, Thiagarajan RR, Reeves MJ, Ritchey M, Rodriguez CJ, Roth GA, Rosamond WD, Sasson C, Towfighi A, Tsao CW, Turner MB, Virani SS, Voeks JH, Willey JZ, Wilkins JT, Wu JH, Alger HM, Wong SS, Muntner P, American Heart Association Statistics Committee and Stroke Statistics Subcommittee: Heart disease and stroke statistics 2017 update: A report from the American Heart Association. Circulation 135(10): e146-e603, 2017.

12 To CY, Rajamand S, Mehra R, Falatko S, Badr Y, Richards B, Qahwash O, Fessler RD: Outcome of mechanical thrombectomy in the very elderly for the treatment of acute ischemic stroke: The real-world experience. Acta Radiol Open 4(9): 1-4, 2015.

13 Parrilla G, Carreón E, Zamarro J, Espinosa de Rueda M, GarcíaVillalba B, Marín F, Hernández-Fernández F, Morales A, Fernández-Vivas M, Núñez R and Moreno A: Recanalization and mortality rates of thrombectomy with stent-retrievers in octogenarian patients with acute ischemic stroke. Cardiovasc Intervent Radiol 38(2): 288-294, 2015.

14 Castonguay AC, Zaidat OO, Novakovic R, Nguyen TN, Taqi MA, Gupta R, Sun CH, Martin C, Holloway WE, MuellerKronast NE, English J, Linfante I, Dabus G, Malisch TW, Marden FA, Bozorgchami H, Xavier A, Rai AT, Froehler MT, Badruddin A, Abraham MG, Janardhan V, Shaltoni H, Yoo AJ, Abou-Chebl A, Chen PR, Britz GW, Kaushal R, Nanda A, A Issa $M$ and Nogueira RG: Influence of age on clinical and revascularization outcomes in the North American solitaire stentretriever acute stroke registry. Stroke 45(12): 3631-3636, 2014.

15 Hwang K, Hwang G, Kwon OK, Kim CH, Ban SP, Han MK, Bae HJ, Kim BJ, Bang JS, Oh CW, Lee B and Jeong EA: Endovascular treatment for acute ischemic stroke patients over 80 years of age. J Cerebrovasc Endovasc Neurosurg 17(3): 173$179,2015$.

16 Khan MA, Baird GL, Miller D, Patel A, Tsekhan S, Yaghi S, Puri A, Jayaraman M, Henninger N and Silver B: Endovascular treatment of acute ischemic stroke in nonagenarians compared with younger patients in a multicenter cohort. J Neurointerv Surg 9(8): 727-731, 2017

17 Goyal M, Menon BK, van Zwam WH, Dippel DW, Mitchell PJ, Demchuk AM, Dávalos A, Majoie CB, van der Lugt A, de Miquel MA, Donnan GA, Roos YB, Bonafe A, Jahan R, Diener HC, van den Berg LA, Levy EI, Berkhemer OA, Pereira VM, Rempel J, Millán M, Davis SM, Roy D, Thornton J, Román LS, Ribó M, Beumer D, Stouch B, Brown S, Campbell BC, van Oostenbrugge RJ, Saver JL, Hill MD, Jovin TG and HERMES collaborators: Endovascular thrombectomy after large-vessel ischaemic stroke: A meta-analysis of individual patient data from five randomised trials. Lancet 387(10029): 1723-1731, 2016.

18Tilley BC, Lyden PD, Brott TG, Lu M, Levine SR and Welch KM: Total quality improvement method for reduction of delays between emergency department admission and treatment of acute ischemic stroke. The National Institute of Neurological Disorders and Stroke rt-PA Stroke Study Group. Arch Neurol 54(12): 14661474, 1997.

19 Ringleb PA, Bousser MG, Ford G, Bath P, Brainin M, Caso V, Cervera A, Chamorro A, Cordonnier C, Csiba L, Davalos A, Diener HC, Ferro J, Hacke W, Hennerici M, Kaste M, Langhorne P, Lees K, Leys D, Lodder J, Markus HS, Mas JL, Mattle HP,
Muir K, Norrving B, Obach V, Paolucci S, Ringelstein EB, Schellinger PD, Sivenius J, Skvortsova V, Sunnerhagen KS, Thomassen L, Toni D, von Kummer R, Wahlgren NG, Walker MF, Wardlaw J, European Stroke Organisation (ESO) Executive Committee and ESO Writing Committee: Guidelines for management of ischaemic stroke and transient ischaemic attack 2008. Cerebrovasc Dis 25(5): 457-507, 2008.

20 Zaidat OO, Yoo AJ, Khatri P, Tomsick TA, von Kummer R, Saver JL, Marks MP, Prabhakaran S, Kallmes DF, Fitzsimmons BF, Mocco J, Wardlaw JM, Barnwell SL, Jovin TG, Linfante I, Siddiqui AH, Alexander MJ, Hirsch JA, Wintermark M, Albers G, Woo HH, Heck DV, Lev M, Aviv R, Hacke W, Warach S, Broderick J, Derdeyn CP, Furlan A, Nogueira RG, Yavagal DR, Goyal M, Demchuk AM, Bendszus M, Liebeskind DS, Cerebral Angiographic Revascularization Grading (CARG) Collaborators, STIR Revascularization working group and STIR Thrombolysis in Cerebral Infarction (TICI) Task Force: Recommendations on angiographic revascularization grading standards for acute ischemic stroke: a consensus statement. Stroke 44(9): 2650-2663, 2013.

21 Banks JL and Marotta CA: Outcomes validity and reliability of the modified Rankin Scale: Implications for stroke clinical trials: A literature review and synthesis. Stroke 38(3): 1091-1096, 2007.

22 Souza LC, Yoo AJ, Chaudhry ZA, Payabvash S, Kemmling A, Schaefer PW, Hirsch JA, Furie KL, González RG, Nogueira RG and Lev MH: Malignant CTA collateral profile is highly specific for large admission DWI infarct core and poor outcome in acute stroke. Am J Neuroradiol 33(7): 1331-1336, 2012.

23 Saarinen JT, Rusanen H and Sillanpää N: Collateral score complements clot location in predicting the outcome of intravenous thrombolysis. Am J Neuroradiol 35(10): 1892-1896, 2014.

24 Campbell BC, Hill MD, Rubiera M, Menon BK, Demchuk A, Donnan GA, Roy D, Thornton J, Dorado L, Bonafe A, Levy EI, Diener HC, Hernández-Pérez M, Pereira VM, Blasco J, Quesada H, Rempel J, Jahan R, Davis SM, Stouch BC, Mitchell PJ, Jovin TG, Saver JL and Goyal M: Safety and efficacy of solitaire stent thrombectomy: Individual patient data meta-analysis of randomized trials. Stroke 47(3): 798-806, 2016.

25 Duffis EJ, He W, Prestigiacomo CJ and Gandhi CD: Endovascular treatment for acute ischemic stroke in octogenarians compared with younger patients: A meta-analysis. Int J Stroke 9(3): 308-312, 2014.

26 Zeevi N, Kuchel GA, Lee NS, Staff I and McCullough LD: Interventional stroke therapies in the elderly: Are we helping? Am J Neuroradiol 33(4): 638-642, 2012.

27 Howard G and Goff DC: Population shifts and the future of stroke: Forecasts of the future burden of stroke. Ann N Y Acad Sci 1268: 14-20, 2012.

28 Hacke W, Kaste M, Bluhmki E, Brozman M, Dávalos A, Guidetti D, Larrue V, Lees KR, Medeghri Z, Machnig T, Schneider D, von Kummer R, Wahlgren N, Toni D and ECASS Investigators: Thrombolysis with alteplase 3 to 4.5 hours after acute ischemic stroke. N Engl J Med 359(13): 1317-1329, 2008.

Received April 12, 2018

Revised May 22, 2018

Accepted May 29, 2018 